\title{
ALGUNAS CUESTIONES JURÍDICAS EN TORNO AL USO DEL CEMENTO ALUMINOSO
}

\author{
(SOME LEGAL QUESTIONS ABOUT THE USE OF HIGH ALUMINA CEMENT)
}

Manuel Olaya Adán, Dr. en Derecho

ICCET/CSIC / ESPAÑA

Fecha de recepción: 11-XI-92

$615-7$

\begin{abstract}
RESUMEN
La problemática jurídica que suscita el uso de un determinado producto o material de construcción tiene sus referencias en una normativa compleja de naturaleza administrativa contemplada en la correspondiente regulación técnica. Tal normativa evoluciona en el tiempo a medida que los conocimientos técnicos y científicos determinan nuevas prescripciones. En el caso de fallos en construcción achacables al uso del material en cuestión, los efectos jurídicos transcienden a ámbitos de responsabilidad civil o, en su caso, penal.

En el presente artículo se analizan diversas cuestiones relacionadas con el caso del uso del cemento aluminoso. El enfoque se circunscribe a exponer el estado del arte durante el periodo en que el material fue empleado en la confección de elementos constructivos prefabricados y se aporta una visión actual de los efectos jurídicos en el ámbito civil a través de tres normas de referencia en la materia.
\end{abstract}

\section{SUMMARY}

The legal issues raised by the use of a particular product or construction material have their references in complex administrative guidelines which take into account the corresponding technical control. Such guidelines develop with the time as the technical and scientific knowledge shapes new ideas. In the case of defects in construction which can be attributed to the use of the material in question, the legal effects reach the field of civil or, where appropriate, penal responsability.

This article analyzes different questions related to the case of the use of high alumina cement. The focus is limited to explaining the state of the art during the period in which the material was used to manufacture precast construction elements. The article brings a current view of the legal effects on the civil field through three reference regualtions.
El presente jurídico se encuentra a veces con la tarea de resolver problemas cuyas causas corresponden a un pasado mediato. La Ley, la Jurisprudencia y la Doctrina, aunque moderadamente, evolucionan, y las referencias del Ordenamiento, que, en su momento (el momento causal), hubieran aportado determinadas soluciones, en parte se han modificado.

La protección de los intereses del consumidor y del usuario en general, y la regulación de las responsabilidades derivadas de los fallos de los productos industriales, son dos grandes áreas del conocimiento jurídico que se han desarrollado a lo largo de este siglo, merced a las corrientes de inquietud de la sociedad norteamericana (1). La recepción europea de estos planteamientos es impulsada en gran medida por el desarrollo de las aplicaciones pacíficas de la energía nuclear (2). La Ley n. ${ }^{0}$ 83-660 de 21 de julio de 1983 relativa a la seguridad de los consumidores, en Francia; The Consumer Safety Act de 1978, modificada por The Consumer Protection Act de 1987, en Gran Bretaña; nuestra Ley de Defensa de los Consumidores y Usuarios de 1984 son, entre otras, las concreciones legislativas en pro del colectivo destinatario final de bienes y servicios. En lo que se refiere a la 
responsabilidad civil por los fallos de los productos defectuosos, la Directiva 85/374/CEE constituye la referencia obligada en el entorno comunitario.

La singularidad de los problemas jurídicos, que conlleva el hecho constructivo, ha determinado tradicionalmente un tratamiento particularizado de los mismos. La obra, en general, ha tenido y sigue teniendo una vía atractiva propia para el Derecho, que se manifiesta en la profusa regulación de los diferentes aspectos que la rodean:

- Reglamentos Técnicos en forma de Instrucciones;

- Normativa Básica, Pliegos de Recepción de materiales, etc;

- atribuciones y responsabilidades de los técnicos;

- regulación de las relaciones contractuales, tanto públicas como privadas;

- garantías posconstrucción;

- limitación de riesgos en la obra, etc.

Sin embargo, ante determinados casos esta legislación puede y de hecho parece ser insuficiente o deficiente.

El objetivo del presente trabajo es el de realizar ciertas consideraciones jurídicas relacionadas con un producto industrial, el cemento aluminoso y la problemática que está suscitando su utilización en un período comprendido entre los años 50-70, como conglomerante hidraúlico, en la confección de elementos estructurales.

El enfoque de este trabajo se circunscribe a la problemática jurídica de la utilización del producto en cuestión, que está dando lugar a patologías en edificios donde se introdujeron en su día los elementos o productos de hormigón resultantes (3).

La valoración de unos hechos y, en su caso, la imputación de responsabilidades correspondiente deben partir de consideraciones sobre lo que se podía conocer en su día sobre la materia. Cuestión distinta es la de referenciar en los instrumentos disponibles legales las conductas. Sobre esta cuestión versarán las reflexiones posteriores.

La óptica jurídica específica en este trabajo se referirá

a planteamientos de orden civil extracontractual.

\section{EL ESTADO DEL ARTE Y LA REGULACIÓN TÉCNICA IMPERATIVA DEL CEMENTO ALUMINOSO Y SUS APLICACIONES}

\subsection{El Estado del Arte en 1964. Los conocimientos científicos en la materia: El Libro de Robson, T.D. "Los cementos aluminosos y sus hormigones" (4).}

La conveniencia de situar en una fecha y en un documento las consideraciones de índole técnica obedece a razones de oportunidad. La obra se inscribe dentro del período al que se ha hecho referencia y, además, es una síntesis del estado del arte en el tema que nos ocupa. De ella vamos a transcribir algunos párrafos, pero previamente conviene hacer algunas consideraciones sobre el conglomerante propiamente dicho.

El cemento aluminoso (C.A.), cemento de alto contenido en alúmina o cemento de aluminato cálcico, es un producto resultante de la sinterización o clinkerización de una mezcla previa de materias primas en la que prevalecen dos componentes: caliza y bauxita. Los procesos para llevar a término la clinkerización son variados, sin embargo el denominador común de los productos resultantes es el aluminato monocálcico $\left(\mathrm{CaO} . \mathrm{Al}_{2} \mathrm{O}_{3}\right)$ como principal constituyente conglomerante. La principal propiedad o característica que puede inducir a privilegiar su utilización en la confección de hormigones para piezas o elementos prefabricados, frente al cemento portland, es la ganancia de alta resistencia en las primeras horas después del amasado. Bajo estas características se pueden identificar distintos tipos de fabricados que se diferencian, por otra parte, además de los procesos de fabricación como se ha dicho, en su composición. Sin embargo, los fenómenos relativos a la evolución de sus resistencias en determinadas condiciones de humedad y temperatura, y las condiciones de amasado idóneas parecen haber sido tratados bajo la misma referencia de cemento aluminoso.

Volviendo al documento de Robson podemos leer en la página 226, en el apartado dedicado al hormigón pretensado, como una de las aplicaciones del producto:

\footnotetext{
"Las ventajas de la alta resistencia inicial obtenida con C.A. (en particular con los de tipo más bajo en sílice) se han aprovechado también en la fabricación de vigas pretensadas, dinteles, viguetas, etc."
} 
En párrafos inmediatos (pg. 227 y ss.), el autor expone una serie de consideraciones al respecto:

"Para trabajo de pretensado debe emplearse siempre el hormigón de C.A. de más alta calidad, y esto lleva consigo métodos vibratorios de compactación. Con este eficiente método de compactación y un buen sistema de control de fábrica (cita el trabajo de Masterman O.J., en Mag. Concr. Res. 1958, 10 (29), 57), se preparan piezas pretensadas comerciales con relaciones agua cemento bajas (menores de 0,40), aun cuando la masa de hormigón sea pobre (por ejemplo 7,5:1 en peso). Cuando no se dispone del equipo adecuado para lograr una compactación vigorosa debe lograrse la docilidad necesaria incrementando el contenido de cemento y no el agua de la mezcla. Mediante ensayos de laboratorio, se ha obtenido información sobre otras propiedades del hormigón de C.A. utilizado para construcciones pretensadas, por ejemplo, resistencia al deslizamiento de los alambres, tensiones de anclaje y adherencia, etc.

El hormigón de C.A. pretensado no se recomienda para su empleo en situaciones donde se sepa de antemano que pueda haber un cierto o probable grado de conversión (5), p.e., mares tropicales o en lugares industriales en los que estuviere bajo agua (o en condiciones de saturación), a una temperatura superior a los $30^{\circ} \mathrm{C}$. Es también de capital importancia que cuando se emplee el C.A. para construcciones pretensadas, la relación agua-cemento nunca debe exceder de 0,45 y, a ser posible, debe encontrarse por debajo de 0,40 . Ya hemos indicado la fluidez relativamente alta de la pasta de C.A. con relaciones agua-cemento bajas y, por lo tanto, es más fácil obtener con el C.A. la docilidad necesaria con bajo contenido de agua que con el cemento portland, o en particular que con el cemento portland de endurecimiento rápido. En la práctica, la mayoría de las vigas de hormigón pretensado de C.A., hechas en Inglaterra, se han fabricado con mezclas cuyas relaciones aguacemento no son superiores a 0,40, y en vista de las buenas propiedades físicas obtenidas con este tipo de hormigón, aun después de una conversión completa, se decidió realizar ensayos sobre vigas de alta calidad fabricadas en condiciones comerciales que, deliberadamente, habían sido conservadas en agua caliente para lograr la completa conversión".

Los ensayos consistieron en la elaboración de dos series de vigas pretensadas, con una relación agua-cemento no superior a 0,40 ; una serie se conservó en agua a $45^{\circ} \mathrm{C}$, aproximadamente durante un mes, y la otra serie se conservó a la intemperie.

La fase de conservación comenzó una hora después del moldeo. Aunque las vigas conservadas a $45^{\circ} \mathrm{C}$ rompieron a menor carga que las conservadas normalmente, los resultados fueron satisfactorios. De estos hechos el autor concluiría:

"Por tanto, parece que el hormigón pretensado de C.A. hecho con una relación agua-cemento suficientemente baja (no mayor de
0,40), es capaz de dar un resultado satisfactorio aunque tenga lugar la conversión completa de los hidratos (6). No obstante, a pesar de esta conclusión favorable, no se considera prudente abrir la mano en las restricciones de uso del C.A. para hormigón pretensado en situaciones que tenga lugar una conversión completa. Los hormigones pretensados de C.A. deberán prepararse y emplearse siempre en condiciones que eludan una rápida conversión; la insistencia en relaciones agua-cemento bajas va dirigida, por tanto, a asegurar un servicio continuado y satisfactorio ante la eventualidad de que pueda tener lugar una posible conversión, bien durante el endurecimiento (p.e., en tiempo caluroso), o bien en el uso normal".

Para explicar los efectos del calor y la humedad y endurecimiento a altas temperaturas y su ligazón con los fenómenos de conversión el autor cita los siguientes trabajos:

Vierheller H. Zement 1927, 16 (28), 602: (29), 649. Rosher Lund, Zement 1927, 16, (34), 747:1929, 18, (23), 718:(24), 748:1931, 20, (8), 164.

Freyssinet E. \& Coyne A. Génie civ. 1927, 90, (11), 266.

Féret R. Rev. Matér. Constr. 1928, (223), 135; (224), 166. Thomas \& Davey D.S.I.R. Building Res. Spec. Reprt n.o 13, 1929. Bates P.H. Inter. Ass. Test Mater. Zurich, 1930, 211. Haegermann G. Tonindustr. Ztg. 1931, 55, (103), 1430. Séailles. 14. Congrés Chim. Industr. París, 1934. Mirnov S. Nov. Tekhn. 1936, (57) 20.

Davey N. D.S.I.R. Building Res. Tech. Paper n.o 14, 1933. Concr. constr. Engng. 1933, 28, (12), 717.

Bolomey J. Bull. tech. Suisse rom. 1927, 53, (24), 285.

Bolomey J. Travaux. 1935, 33, 384.

Davey N. Intern. Ass. Test Mater. London, 1937, 342.

Ann. Report Building Res. Board, England 1928, H.M.S.O. Séailles C.R. Acad. Sci. París 1932, 195, (16), 662. Lafuma H. C.R. Acad.

Sci. París, 1933, 196, (22), 1671. Von Polheim E.P. Zement 1935, 609, 643, 659, 677.

Ann. Report Building Res. Board, England 1933. H.M.S.O. SéaiIles Ref. n.o 48 Iltchnenko N. \& Lafuma. Chim. et Industr. 1937, 38, (3), 438.

Couillaud E. C.R. Inst. Bâtim. 1939, 209, (8), 397. Thesis, París, 1947. Ann. Inst. Bâtim. Circ. Sér. F. 1947, n.o 31.

Lea F.M. J. Soc. Chem. Industr. 1940, 59, 18.

Wells L.S. \& Carlson E.T. J. Res. nat. Bur. Stand. 1956, 57 (69, 335 RP. 2723 - Segalova Z.D. Tulovskaya E.A. Amelia \& Rebinder P.A. C.R. Akad. Sci. URSS, 1959, 124, 876.

Fricke R. anorg. Chem. 1928, 175, 249 H.B. Weiser \&W.O. Milligan J. Phys. Chem, 1934, 38, 1175, Funaccki K. \& Shimizu J. Chem. Soc. Japan 1952, 35, 194 Suzuki Koloidzschr., 1958, 156, (19, 67. Papée D., Tertiau \& Biais. Bull. Soc. Chim. Fr 1949 11-12, 1301. Sato T. J. Appl. Chem. London. 1961, 2, (6). 
Travers \& Leduc C.R. 1933, 97, (39), 252: 1934, 198, (9), 828. Iltchenko \& Lafuma. ref. n. 54. Couillaud. Ref. n. 55.

Lafarge Aluminous Cement Co Ltd. Davey, Ref. n. 52 . Building Res. station Digest. n. 27. 1951. H.M.S.O.

Gottlieb S. Cement \& Lime Manuf. 1940, 13, (4), 55. Neville A.M. Proc. Instn. civ. Engrs. 1958, 10, 185.

Hagger G.C. J. Instn. civ. Engrs, 1945, 25, 142 Concr. constr. Engng, 1946, 41 (8), 210.

Robson T.D. Architect. Science Rev. Sydney, 1959, 2, (1), 49, Newman. Ref. n.o 1 .

Masterman O.J. Civ. Engng. \& publ. Works Rev. 1961, 56, (657), 483.

Schneider S.J. J. Amer. ceram. Soc. 1959, 42, (4), 184.

Ciments Lafarge. París.

Brocard J. C.R. Acad. Sci. París, 1951, 232, (5), 413.

Lafuma H. Ann. Chim. appl. Roma. 1954, 44, 719.

Noto la Diega Il Cemento, 1959, 7, 23.

Budnikov P.P. \& Gol' denberg I.G. Dopodivi Akad Nauk URSS Phys. Chem. 1942, (3-4), 73, J. Chem. Moscow, 1945, 18, 15, 1959, 32, 21.

Soc. Anon des Chaux et Cim. Lafarge, Brit. Pat. 317783, 1929.

Ashai Glass Co. Ltd. Koide, Amato \& Nishida, Japan Pats. 5431, 5432, 5433. 1949. Koide, Komata \& Kawano Asahi Glass Co. Res. Lab. Rep, 1, 6, 133.

Sersale R. Ric. Sci. 1957, 27, 777. Adamovich. Doki. Akad. nauk URSS. 1955, 103, 853 N.G. Zaitseva \& Smirnova, Kolloid Zhur. 1958, 30, 636.

Budnikov. Russian Pat. 57563, 1940. See also Russ. Pats. 127603 , 127607.

Clarkson P. Engng. London. 1951, 345. Collins A.R. Ref. n.o 6. Budnikov P.P. \& Kravchenko I.V. Kolloid Zhur. 1959, 21, (1), 9.

"The Technology and Properties of Heavy Concrete". Ed. Desov E.V., 1959. In Russian: State Publishing Office for Literature on Building, etc.

Peppler R.B. \& Wells L.S. J. res. nat. Bur. Stand. 1954, 52, (2). Etc.

1.2. La referencia a normas técnicas y reglamentaciones entre 1945 y 1970.

En Alemania, según el documento Beton-Kalender 1945-50 (Ed. Wilhelm Ernst \& Sohn, Berlín) pg. 82, el C.A. (Tonerdezement), fabricado con la marca comercial "Rolandshüte", figura como no normalizado. Sin embargo, para su utilización, aparte de recomendaciones relativas a la proscripción de su empleo mezclado con ( ) Consejo Superior de Investigaciones Científicas

Licencia Creative Commons 3.0 España (by-nc) otros cementos, con cal o agua de mar, se indican como normas técnicas de referencia las siguientes: DIN 1045, 5, Ziff. 3, DIN 1164 con referencia al tipo de cemento 425 .

En 1962, el Ministerio de Finanzas y Reconstrucción de Rheinland Pfalz, mediante una circular de 1 de marzo, advierte sobre la evolución anómala de las resistencias del hormigón de C.A., bajo condiciones de humedad y temperatura desfavorables, en un período de un año. Respecto a las condiciones de utilización, la misma circular hace referencia a las siguientes normas técnicas:

DIN 1045, 5.3 / 2 Ed. nov. 1959

\section{$5.5 / 2$ \\ 5.9}

\section{DIN 1058 Ed. jul. 1959}

En Francia, en 1966 no consta la normalización técnica del cemento aluminoso. Sin embargo, el Ministerio de Obras Públicas, en circular de 5 de enero de 1943, prohibe el empleo en la construcción de puentes de autopistas, canales de navegación $y$ en obras marítimas.

En Italia, la regulación del C.A. aparece recogida en el Decreto de 16 de noviembre de 1939.

1.3. La situación en España en el período 1930-1980.

En España, la reglamentación tiene sus orígenes en el Pliego de Condiciones para la recepción de aglomerantes hidráulicos en obras oficiales (aprobado por R.O. de 25 de febrero de 1930), que en el capítulo II, Cementos de Gran Resistencia, refiriéndose a los cementos aluminosos dispone:

"Se llama cemento aluminoso al obtenido por la cocción de una mezcla íntima de la que son elementos esenciales la bauxita y el carbonato de cal, siempre que en el producto resultante la cantidad de alúmina sea inferior al cuarenta por ciento y superior al treinta, y la de óxido de hierro no exceda del dieciocho por ciento".

Art. 8.: Finura de molido.-Dejará un residuo insoluble de cinco décimas por ciento en el tamiz de novecientas mallas y menos de seis por ciento en el de cuatro mil novecientas mallas.

http://informesdelaconstruccion.revistas.csic.es 
Art. 9.: Peso especifico real.-Será superior a tres con cinco centésimas.

Art. 10: Fraguado.-No empezará antes de los treinta minutos, ni terminará después de las cuatro horas de amasado.

Art. 11: Estabilidad de volumen.-Las galletas fabricadas con pasta pura, con la dosificación de agua suficiente determinada por ensayos previos, no acusarán grietas superficiales después del fraguado.

Art. 12: Resistencias.-Con probetas en forma de ocho fabricadas con pasta pura, la tracción media en series de seis probetas no será inferior a ventiocho kilogramos por centímetro cuadrado a las veinticuatro horas y llegará a sesenta kilogramos por centímetro cuadrado a los tres días.

En hormigones compuestos de gravilla entre uno y dos centímetros y arena silícea de grano comprendida entre uno y uno y medio milímetros, dosificando a razón de ochocientos cuarenta litros de gravilla, cuatrocientos litros de arena, trescientos kilogramos de cemento y ciento treinta litros de agua, formando probetas cúbicas de veinte centímetros de arista, comprimidas con treinta golpes de maza de cinco kilogramos de peso, cayendo de veinte centímetros de altura, la resistencia a la compresión deberá exceder de las cifras siguientes:

A las veinticuatro horas: 220 kilogramos por centímetro cuadrado.

A los veintiocho días: 230 kilogramos por centímetro cuadrado."

- El Pliego de 1959 (Orden de 31 de diciembre de 1959), modifica el contenido de la definición: “...conglomerantes hidráulicos obtenidos por fusión de una mezcla de materiales aluminosos y calizos,...". También introduce la designación CA-350 (350 kg por centímetro cuadrado, en resistencia a compresión a las 24 horas del mortero normalizado).

- En 1944, la Orden ministerial de 20 de marzo establece la Instrucción para el proyecto de obras de hormigón. En su artículo 19, párrafo 5. dice: "El hormigonado se suspenderá cuando la temperatura del ambiente sea superior a cuarenta grados o a treinta y cinco si se emplea cemento aluminoso".
- El Pliego de 1964 (Orden de 9 de abril de 1964) mantiene las mismas definiciones y designación.

- La Instrucción para el proyecto y la ejecución de obras de hormigón en masa o armado (Decreto 20 de septiembre de 1968) (7) establece en su artículo 5, $2^{\circ}$ párrafo: "El empleo del cemento aluminoso deberá ser objeto en cada caso de justificación especial".

- La Instrucción EH-73, para el proyecto y la ejecución de obras de hormigón en masa o armado es el documento regulador del empleo del cemento aluminoso de mayor relevancia hasta entonces. A través de él se puede percibir un gran salto cualitativo en la normativa. En el artículo 5.1, párrafo 2. ${ }^{\circ}$ se puede leer: "El empleo del cemento aluminoso deberá ser objeto en cada caso de estudio especial, exponiendo las razones que aconsejan su uso y observándose estrictamente las especificaciones contenidas en el anejo 4". Tales especificaciones hacen referencia entre otras prescripciones al empleo de relaciones agua-cemento menores de 0,4 , dosificaciones de cemento superiores a $400 \mathrm{~kg}$ por metro cúbico, temperatura del hormigón, recién preparado, menor de $22^{\circ} \mathrm{C}$, prohibición de curado térmico, etc.

- En el Pliego de 1975 (Decreto de la Presidencia del Gobierno 1964/75, de 23 de mayo) se introduce la noción de Crudo de C.A.: “... mezcla suficientemente fina y homogénea, obtenida a partir de calizas y bauxitas de composición idónea,..." Los cementos aluminosos se definen como aquellos que se obtienen por molturación de su clínker. Se introduce la Denominación Cemento Aluminoso 550 y la designación A-550 (resistencia referida a 28 días). Respecto a los datos que deben figurar en el albarán (cementos a granel) o impresos en los sacos, se citan:

a) Nombre del fabricante o marca comercial del cemento.

b) Designación del cemento, según el Pliego.

c) Clase y límite de porcentaje de las adiciones activas (en los casos de Portland con Adiciones Activas, Siderúrgicos o Puzolánicos.

d) La inscripción "No apto para estructuras de hormigón", en el caso de que se trate de cementos compuestos.

e) Peso neto.

En el Pliego se normaliza el etiquetado. 
- En lo referente al hormigón pretensado, en el año 1977, mediante la primera Instrucción para el Proyecto y la ejecución de obras de hormigón pretensado, EP-77, se proscribe el empleo del C.A. para los elementos construidos con esta técnica.

\section{LA ÓPTICA JURÍDICA COMUNITARIA ACTUAL EN RESPONSABILIDAD POR DAÑOS PRODUCIDOS POR EL FALLO DE PRODUCTOS DEFECTUOSOS. LA DIRECTIVA 85/374/CEE, DE 25 DE JULIO DE 1985}

La necesidad de unificar el derecho de daños en los Estados miembros de la CE, de cara a la consecución del Mercado Único, determinó el modelo legislativo materializado en la Directiva 85/374 (8). En ella se establece un criterio objetivo de imputación de la responsabilidad (Art. 1, "El productor será responsable de los daños causados por los defectos de sus productos").

La definición de producto, según el artículo 2, es la siguiente: "cualquier bien mueble, excepto las materias primas agrícolas y los productos de la caza, aun cuando esté incorporado a otro bien mueble o a uno inmueble". En el artículo seis se establece lo que debe entenderse por producto defectuoso: “...cuando no ofrece la seguridad a la que una persona tiene legítimamente derecho, teniendo en cuenta todas las circunstancias, incluso:

a) la presentación del producto;

b) el uso que razonablemente pudiera esperarse del producto;

c) el momento en que el producto se puso en circulación".

En lo referente a la presentación del producto, hay que entender que por una parte el embalaje o envase debe ser el idóneo y, por otra, que debe ir acompañado de las correspondientes instrucciones de manipulación y uso, destacando las circunstancias que son desfavorables o que acarrean determinados riesgos.

Por productor se entienden tanto la persona que fabrica un producto acabado, que produce una materia prima o que fabrica una parte integrante, como aquellas personas que se presenten como productores poniendo su nombre, marca o cualquier otro signo distintivo en el producto (art. 3.1.). También el importador de un pro- ducto o, caso de que el productor no pueda ser identificado, cualquier suministrador es considerado productor (art. 3.2 y 3).

La acción de resarcimiento prescribe en el plazo de tres años a partir de la fecha en que el demandante tuvo, o debiera haber tenido, conocimiento del daño, del defecto y de la identidad del productor (art. 10.1).

La cuestión de la caducidad del derecho a la reclamación ofrece una peculiaridad específica, ya que se cifra en un período de diez años a partir de la fecha en que el productor hubiera puesto en circulación el producto mismo que causó el daño, a no ser que el perjudicado hubiera ejercitado una acción judicial contra el productor (art. 11).

Por otra parte el productor no es responsable, entre otras causas, si prueba "que el defecto se debe a que el producto se ajusta a normas imperativas dictadas por los poderes públicos; o que, en el momento en que el producto fue puesto en circulación, el estado de los conocimientos científicos y técnicos no permitía descubrir la existencia del defecto; o que, en el caso del fabricante de una parte integrante, el defecto sea imputable al diseño del producto a que se ha incorporado o a las instrucciones dadas por el fabricante del producto" [art. $7 \mathrm{~d})$, e) y f)]. Por normas imperativas hay que entender las reglamentaciones técnicas. Respecto al 'estado de los conocimientos técnicos y científicos', cabe entender la normativa técnica y las publicaciones relevantes en la literatura científica internacional. Particularmente interesante, para el tema que nos ocupa, es la causa de exoneración a la que se refiere el apartado b) del mismo artículo: 'o que teniendo en cuenta las circunstancias, sea probable que el defecto que causó el daño no existiera en el momento en que él (el fabricante) puso el producto en circulación o que este defecto apareciera más tarde.

El perjudicado deberá probar el daño, el defecto y la relación causal entre el defecto y el daño (art. 4).

Respecto a la naturaleza y entidad de los daños, el artículo 9 establece:

“a) los daños causados por muerte o lesiones corporales;

b) los daños causados a una cosa o la destrucción de una cosa que no sea el propio producto defectuohttp://informesdelaconstruccion.revistas.csic.es 
so, previa deducción de una franquicia de 500 ECUS, a condición de que tal cosa:

i) sea de las que normalmente se destinan al uso o consumo privados

\section{y}

ii) el perjudicado la haya utilizado principalmente para su uso o consumos privados".

Los daños resultantes de accidentes nucleares y que estén cubiertos por convenios internacionales ratificados por los Estados miembros quedan fuera del ámbito de aplicación de la Directiva (art. 14).

2.1. Las cuestiones jurídicas en el tema que nos ocupa, a la luz del régimen de responsabilidad civil de la Directiva

La propia Norma en su artículo 17 estable "La presente Directiva no se aplicará a aquellos productos que se pongan en circulación antes de la fecha en que entren en vigor las disposiciones a que se refiere el artículo 19". Es decir, antes de tres años de ser notificada a los Estados miembros. Por otra parte las disposiciones no han sido transpuestas al Ordenamiento español (9). No obstante, a la luz del articulado se pueden destacar una serie de consideraciones, que vamos a tratar de exponer a continuación.

En primer lugar conviene hacer una crítica al texto comunitario desde el punto de vista del caso de la aplicación inadecuada del producto C.A. El período de diez años previsto en esta Directiva, desde que el productor puso el producto en circulación, para la caducidad del derecho a la acción de resarcimiento hubiera sido insuficiente en el caso que nos ocupa, que en este sentido sería conveniente revisar; en el caso de productos cuya evolución en el tiempo diera lugar a cambios sustanciales en las características, en función del contexto físicoquímico; la duración del período antedicho, máxime cuando (como es el caso de la construcción) tales productos suelen quedar incorporados, de forma inaccesible, para el usuario de la obra.

La segunda consideración parte del hecho de que, si la Directiva (haciendo uso de la ficción) hubiera sido aplicable (entendiendo por tal aplicabilidad la legislación na- cional derivada), lo hubiera sido tanto al cemento aluminoso como a los productos resulantes. Por otra parte, como se ha expuesto en el primer epígrafe, la literatura científica era, a la altura de 1964, suficientemente abundante sobre los fenómenos conexos al fraguado y endurecimiento del C.A.; no lo era así la normativa técnica. Respecto a las normas imperativas, es decir, los Pliegos generales para la recepción de los conglomerantes hidráulicos y las Instrucciones para el proyecto y ejecución de obras de hormigón, aunque las referencias al material en sí y a su aplicación se remontan a las épocas cercanas a su producción comercial, no existe una regulación relevante hasta el año 1983. Se puede decir que existían grandes lagunas en la legislación administrativa en esta materia entre 1950 y 1970 , período en que se referencia el uso inadecuado del producto; ello podría ser valorado como circunstancia exoneradora según el apartado d) del art. 7, recayendo la responsabilidad en la Admón. del Estado. Sin embargo, esta reflexión tiene que ser matizada, ya que la regulación, aun con las grandes lagunas, pudo haber sido suficiente para haber evitado el uso inadecuado del C.A.; convendría por tanto saber las causas que, en cada caso, fueron el origen de la patología posterior. En 1950 ya se contemplaban en las normas imperativas, como se ha visto anteriormente, ciertas precauciones, tanto en las dosificaciones como en el hormigonado en tiempo caluroso. Por otra parte, contemplar en este caso la circunstancia exoneradora del art. 7 apdo. (ya que así está contemplado en el texto al utilizar la partícula 'o' en vez de ' $y$ ', en lo referente a las posibilidades de prueba que tiene el productor entre las distintas circunstancias) conlleva un nuevo argumento crítico al texto comunitario. En este caso se pone en evidencia que la prueba tendría que ser no sólo del cumplimiento de las normas imperativas, sino también de haber tenido en cuenta el estado de los conocimientos técnicos y científicos en el momento de poner los productos en circulación (art. 7.e).

Al hilo de la anterior consideración cabe decir que la no referencia en el etiquetado (albarán o saco) a los riesgos en el empleo del material en cuestión, serían causa suficiente para considerar defectuoso el producto a la luz de la regulación que establece la Directiva (art. 6).

Respecto a la exoneración contemplada en el apdo. b) del art. 7 cabe decir que, según la misma, la relevancia jurídica del momento en que el producto es puesto en circulación resulta clave, ya que (10) el fabricante es res- 
ponsable, según el régimen de la Directiva, no ya por la fabricación, sino por la puesta en circulación del fabricado. En el caso que estamos tratando, la cuestión se desplaza al interés jurídico que puede tener el caso de los productos a base de hormigón, ya que dada la naturaleza de tales productos, el material evoluciona a lo largo del tiempo en sus características esenciales; es más, zoncurriendo durante ese período sobre el producto fenómenos ajenos como consecuencia de estar expuesto a ambientes agresivos (p.e. fenómenos de carbonatación); la cuestión sería si en este caso se puede pensar en la aplicación de la exoneración. La Directiva tan sólo ayuda a dar respuesta a esta cuestión con la coletilla que abre el texto del apdo., es decir 'o que según las circunstancias...'. La exoneración, pues, no está planteada en términos absolutos sino que dependerá de la casuística específica.

Por otra parte, aunque la legislación derivada de la Directiva no fuese aplicable, su propio texto remite a los Ordenamientos nacionales. En este sentido, el artículo 13: "La presente Directiva no afectará a los derechos que el perjudicado pueda tener con arreglo a las normas sobre responsabilidad contractual o extracontractual o con arreglo a algún régimen especial de responsabilidad existentes en el momento de la notificación de la presente Directiva".

En España, la legislación civil relevante en el derecho de daños es la norma del artículo 1902 del Código Civil y la Ley 26/84, para la Defensa de los Consumidores y Usuarios. Cabe recordar, que este trabajo está circunscrito en la esfera del producto C.A. y de los productos derivados, sin argumentar sobre las eventuales implicaciones de otros agentes participantes del hecho constructivo (11).

\subsection{En torno a la aplicación del art. 1902 del C.C.}

"El que por acción u omisión causa daño a otro interviniendo culpa o negligencia, está obligado a reparar el daño causado". Esta norma sintetiza el derecho de daños de procedencia extracontractual en el Código Civil español. Sin embargo, frente a los hechos derivados de la producción masiva y de los riesgos que la misma conlleva, habida cuenta de la complejidad de medios tecnológicos y de la dificultad que a veces entraña el control de los procesos, su aplicación basada en la existencia de (c) Consejo Superior de Investigaciones Científicas

Licencia Creative Commons 3.0 España (by-nc) una persona o personas físicas culpables, con una relación de causalidad probada, entre su acción y el daño, conlleva grandes dificultades para quien ha resultado perjudicado por fallos de productos industriales a la hora de obtener el resarcimiento. Todo ello ha ido conduciendo a la Jurisprudencia y la Doctrina (12) a apuntar soluciones tales como la inversión de la carga de la prueba de la culpabilidad o el reconocimiento de un cierto grado de objetividad en casos específicos relacionados con los riesgos del progreso.

Los requisitos generales de la imputación en la responsabilidad aquiliana, recogidos por la Jurisprudencia siguen siendo: una actuación negligente o reprochable por falta de previsión, una infracción del deber objetivo de cuidado, una lesión o daño y una relación de causalidad entre el proceder negligente o descuidado y el daño sobrevenido. Por tanto, el factor sicológico o moral sigue teniendo peso en la valoración jurídica a la hora de aplicar el artículo 1902. Bien es cierto que tratándose de actividades peligrosas, que generan un lucro para el agente, la tendencia de la Jurisprudencia es la de adoptar criterios objetivistas en pro del resarcimiento del daño ocasionado. Es más, ni tan siquiera se admite, en determinados casos, la prueba de que se ha obrado diligentemente por haber cumplido normas reglamentarias, ya que se entiende que, si la actividad puede conllevar determinados riesgos, los esfuerzos en la aportación de garantías para evitar tales riesgos tienen que ser valorados según la magnitud del o de los daños.

La sentencia de la Sala 1.a del TS, de 14 de mayo de 1963, en relación con la calificación jurídica de los actos causales de daños civiles, contiene entre sus considerandos lo siguiente: “....un acto lícito, en sí, da lugar a que se preste la culpa si no se realizó con la prudencia que las circunstancias requieren y por tanto no puede estimarse lícito el hecho de autos... cuando hay medios técnicos para evitarlo". En la misma sentencia se hace alusión a la irrelevancia de que los hechos hayan tenido lugar cumpliendo reglamentos y sigue, al efecto, el criterio de la sentencia de la misma Sala, de 23 de diciembre de 1952.

La sentencia de 10 de febrero de 1959 (TS, S. 1.a), refiriéndose al nexo causal: "Puede deducirse que cuando los hechos sucesivos están íntimamente ligados entre sí, que cada uno de ellos sea consecuencia tan lógica y natural del anterior, que sin su concurrencia no se hubiera producido racionalmente, persiste el nexo causal, a diferencia de cuando esa concatenación de hechos aparece rota por la interferencia de actos no directamente derivados del anterior, en que desaparece la relación de causalidad y con ello la responsabilidad derivada del acto originario". http://informesdelaconstruccion.revistas.csic.es 
Sobre lo que debe ser entendido por comportamiento negligente, la sentencia de 9 de junio de 1969, “...Que conforme a lo dispuesto en el párrafo 1 del artículo 1104 del C. civ., la culpa o negligencia consiste en la omisión de aquella diligencia que exija la naturaleza de la obligación y corresponda a las circunstancias de las personas del tiempo y del lugar". En el caso del artículo 1902 la obligación legal consiste en "tener presente el alterum non laedere".

Respecto a la responsabilidad objetiva en las actividades con riesgo, la sentencia de 24 de marzo de 1953 “...la jurisprudencia viene imprimiendo a la referida responsabilidad civil un cierto matiz objetivista en el sentido de exigir una vigorosa prueba de la diligencia desplegada por el empresario en cada caso concreto para desvirtuar la presunción de culpabilidad, sin que a tal fin sea eficaz el mero cumplimiento formulario de preceptos reglamentarios que tienden a prevenir los siniestros...". Sobre este mismo tema, las sentencias de 20 de octubre de 1963, 23 de marzo de 1968, 11 de marzo de 1971, 14 de marzo de 1978, etc.

La norma del art. 1902 ha dado respuesta en nuestro Derecho al problema de los daños causados por fallos de productos ${ }^{13)}$. Su aplicación está en función del plazo de un año a partir de cuando el perjudicado sabe del daño (art. 1968.2). A diferencia del sistema de responsabilidad de la Directiva 85/374, nuestro Código Civil no establece término alguno, desde que los hechos causales tuvieron lugar, para la caducidad del derecho a ejercitar la acción de resarcimiento.

Sobre la prescripción extintiva, en el caso de daños continuados, las sentencias de 12 de diciembre de 1980 y de 16 de enero de 1989.

\subsection{La Ley $26 / 84$ para la Defensa de los consumidores y usuarios.}

El apdo. 1 del artículo $1 .^{\circ}$ define quiénes son los sujetos a los que la Ley ampara: "son consumidores o usuarios las personas físicas o jurídicas que adquieren, utilizan o disfrutan, como destinatarios finales, bienes muebles o inmuebles, productos, servicios, actividades o funciones, cualquiera que sea la naturaleza pública o privada, individual o colectiva, de quienes los producen, facilitan, suministran o expiden".

Los artículos 41 y 42 atribuyen competencias a las Comunidades Autónomas y a las Entidades locales para promover y desarrollar la protección y defensa de los consumidores y usuarios de su ámbito, por lo que habrá que estar a la disposición de cada una de éstas en lo que se refiere a las actuaciones específicas en el tema que nos ocupa (14).

El capítulo VIII establece el régimen de garantías y responsabilidades. Con él se ha pretendido la vigorización del sistema de responsabilidad civil establecido por los artículos 1902 y 1903 (15). Sin embargo existen en el mismo, aparte de grandes deficiencias técnicas, ambigüedades que en nada favorecen su interpretación, tales como el aparente plus de responsabilidad que introduce el artículo 28 sobre el 25 , o la generalidad con que se plantea la eventual imputación de aquellos que cita el art. 27.

En el tema que nos ocupa, esta Ley no aporta ningún criterio que ayude a analizar la problemática de los daños diferidos ni tan siquiera ilumina planos específicos relativos a la prescripción de las acciones, ni sobre qué productos, en relación con su fecha de fabricación, se debe de aplicar. Cabe entender, que la ley no es retroactiva y que, por lo tanto, quedan excluidos de ella aquellos hechos del pasado que han derivado en una patología presente.

En lo que respecta al problema de la posible implicación de la Administración, cuando los productos que están sometidos a su intervención fallan causando daños, el capítulo octavo no introduce ninguna luz. En principio, y en lo que respecta al fabricante (también al importador, suministrador o facilitador en general), la situación es diferente a la del sistema establecido por la Directiva 85/374, que tuvimos ocasión de exponer anteriormente. En este caso, para exonerarse tendrá que hacer constar o acreditar que se han cumplido debidamente las exigencias y requisitos reglamentariamente establecidos y "los demás cuidados y diligencias que exige la naturaleza del producto, servicio o actividad". Tan sólo parece clara la implicación de la Administración en el caso de que el daño causado por el fallo del producto hubiera podido evitarse con la preceptiva intervención administrativa (16). Resulta de mayor complejidad el problema de la co-participación al daño, por la casuística profusa de la Administración y de sus agentes colaboradores. En el caso de reglamentación insuficiente, existiendo antecedentes científicos sobre determinados riesgos, puede ser uno de los casos de co-participación. 


\section{NOTAS}

(1) En lo que respecta al consumidor, The Jungle, de Upton Sinclair (1906) constituye un hito literario en pro de su defensa. Otras obras posteriores (Your Money's Worth, 1927; Skin Deep, 1934 American Chamber of Horrors, 1936; etc., son muestras de la preocupación por el tema.

El caso Mac Pherson vs. Buick Motor, en la Corte de Apelación de Nueva York (Juez Cardozo, 1916), constituía el primer caso en que se desvinculaba la responsabilidad del producto de la relación contractual previa.

En la década de los setenta se materializan dos importantes textos legales: The Uniform Product Liability Act y The Consumer Product Safety Act.

(2) Sobre estos aspectos, el relevante trabajo de ROJO FERNÁNDEZ RÍO “La responsabilidad civil del fabricante". Bolonia, 1974; Zaragoza, 1984

(3) Los fenómenos químico-físicos que están en la raíz de tal patología corresponden a los siguientes procesos: $\mathrm{Al}$ mezclar el cemento aluminoso con agua se forma el compuesto aluminato monocálcico hidratado, $\mathrm{Al}_{2} \mathrm{O}_{3} \cdot(\mathrm{CaO}) \cdot 10 \mathrm{H}_{2} \mathrm{O}$, que cristaliza en el sistema hexagonal, en estado metaestable. Con aumento de temperatura, puede convertirse en el compuesto $\mathrm{Al}_{2} \mathrm{O}_{3} \cdot 3(\mathrm{CaO})$. $.6 \mathrm{H}_{2} \mathrm{O}$ que, pese a ser ya estable con estructura cristalina en el sistema cúbico, el proceso de conversión se produce con reducción de volumen y pérdida de agua, por lo tanto con un aumento de la porosidad del hormigón resultante que, lógicamente, pierde resistencia. Si además, el elemento de hormigón se encuentra en un ambiente carbónico con presencia de humedad, dada la elevada porosidad se producen fenómenos de carbonatación, es decir, se va perdiendo la reserva alcalina al formarse los correspondientes carbonatos, pudiendo llegar, con el tiempo, a que las armaduras del elemento pierdan su protección, corroyéndose finalmente. (Síntesis facilitada por el Profesor de Investigación Vázquez Moreno).

(4) El libro, traducido al castellano por el hoy profesor D. Francisco Soria Santamaría, del CSIC, apareció en 1965, publicado por la Editorial Carcamo Hermanos y Cr. Book Ltda. En su prólogo se puede leer "Estimado en sus principios por su resistencia a los sulfatos (probablemente, hoy día, es destacado en este aspecto) el cemento aluminoso reveló pronto cualidades de endurecimiento excepcionales, creando de este modo un interés considerable en su empleo para estructuras de hormigón. Se han discutido ampliamente las ventajas y limitaciones de este tipo de cemento para obras estructurales en ciertas condiciones cli(C) Consejo Superior de Investigaciones Científicas Licencia Creative Commons 3.0 España (by-nc) máticas e industriales, junto con los principios en los que se basan. Un mayor entendimiento de estos principios deberá conducir al correcto uso del cemento aluminoso si son necesarias sus propiedades de endurecimiento rápido o resistencia química".

(5) Fenómeno causal asociado a la pérdida de resistencias del hormigón de C.A., el autor dedica a este tema las páginas 127 a 145. Sobre la visión actual de los fenómenos, ver nota 3.

(6) Los fenómenos de conversión se controlaron con cubos de hormigón conservados en agua caliente. La conversión se produjo antes del mes.

(7) Mediante la misma se derogaban, transcurrido el período de dos años, la Instrucción precendente de 1944 y las siguientes disposiciones: Ordenes de 18 de marzo (edificaciones militares) y de 10 de septiembre de 1941 (Normas técnicas de proyecto y construcción de edificios), ambas del Ministerio del Ejército y las Normas para el cálculo y ejecución de estructuras de hormigón armado de la Dirección Gral. de Arquitectura de Nov. de 1941.

(8) La Directiva ha sido transpuesta a la legislación nacional de varios Estados miembros: Gran Bretaña, Grecia, Luxemburgo, Alemania, Italia, Dinamarca, Portugal, etc. Ello significa que es legislación aplicable a los fallos de los productos que tengan lugar en los respectivos territorios, cuando tales fallos den lugar a daños de los previstos en la Directiva.

(9) Respecto al llamado "efecto directo de las directivas", la Jurisprudencia del Tribunal de Justicia de la CE es copiosa. Una Directiva que no ha sido transpuesta por un Estado miembro, en el plazo previsto en su articulado, estando su contenido planteado en términos inequívocos, tiene efectos jurídicos en las reclamaciones frente al Estado incumplidor (eficacia vertical), mientras que se plantea como dudosa la eficacia frente a los ciudadanos de ese Estado (eficacia horizontal). Entre otros, el caso Ratti, 5 de abril de 1979. Otras sentencias anteriores, en la misma línea, subrayando la primacía del Derecho comunitario: el caso Van Gend \& Loos, de 5 de febrero de 1963, el caso Costa C. ENEL, de 14 de julio de 1964, el caso Simmenthal, de 9 de marzo de 1978, etc.

(10) Alcover Garau G. "La responsabilidad civil del fabricante. Derecho comunitario y adaptación al Derecho español". Ed. Civitas. pp. 117 y ss. 1991.

(11) Respecto a este tipo de argumentos, el trabajo de Rafols Llach J. "Problemática jurídica i legal", en las Jornades técniques sohttp://informesdelaconstruccion.revistas.csic.es 
bre il cement aluminós i els seus prefabricats, Barcelona, 1991. Collegi d' Aparelladors-Arquitectes Técnics de Barcelona.

(12) Cavanillas Mújica "La transformación de la responsabilidad civil en la Jurisprudencia”. Ed. Aranzadi. 1987.

Pascual Estevill, L. "Hacia un concepto actual de la responsabilidad civil”. Ed. Boch. 1989.

(13) Sentencias al respecto (TS, S 1. a): la de 14 de octubre de 1972 (explosión de un barril de cerveza), de 12 de mayo de 1976 (en relación con fallo de una bombona de gas butano), de 5 de octubre de 1979 (accidente en suministro de gas), así como las de 15 de octubre de 1983, 29 de marzo de 1983, 14 de noviembre de 1984, etc. Sobre la acogida de los nuevos planteamientos en el tema de daños por productos, la sentencia de 26 de enero de 1990 (defecto de fabricación de armario por daño como causa de muerte por electrocución).
(14) Lo referente a la delimitación de competencias de las CCAA, en materia de protección al consumidor, así como a las cuestiones de constitucionalidad planteadas alrededor de esta Ley han sido temas objeto de la Sentencia del Tribunal Constitucional de 26 de enero de 1989.

Un estudio profundo del texto legal en "Comentarios a la Ley general para la defensa de los consumidores y usuarios "(Bercovitz, Salas y otros). 1992.

(15) Sentencia AP de Valencia S. 7a . 23 de octubre 1989.

(16) Parra Lucan, M.A. "Daños por productos y protección del consumidor”. Ed. J. M. ${ }^{a}$ Boch Editor, S.A. Barcelona 1990. La autora profundiza sobre el tema (pp. 428-431) citando el art. 106.2 de la Constitución. También, en el mismo sentido, el artículo 40 de la Ley de régimen jurídico de la Administración (Texto refundido en Decreto de 26 de julio de 1957).

\section{publicaciones del ICCET / CSIC}

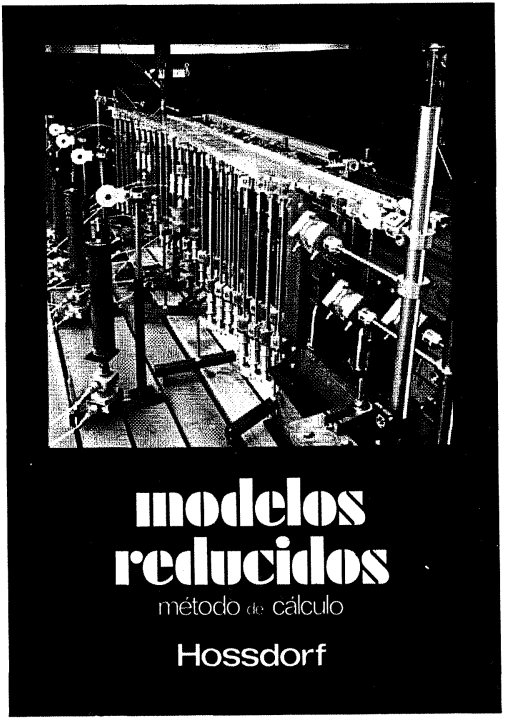

Modelos reducidos. Método de cálculo

H. Hossdorf, Ingeniero Civil

La técnica de los ensayos en modelos reducidos de estructuras sufre hoy dia una decisiva metamorfosis. Hasta hace poco era un medio más bien de artesania, que no siempre era tomado en serio por los academicos teorizantes Dara comprender el comportamiento resistente de las estructuras complejas y al que se acudió las más de las veces, como a un último remedio debido a sus indiscutibles insuficien cias. Sin embargo, en poco tiempo y gracias a su conexión con los ordenadores digitales, se ha trans formado en un instrumento cientificamente valioso, que no puede quedar a un lado en la práctica diaria del Ingeniero Proyectista.

Un volumen encuadernado en cartoné plastificado con lomo de tela de $17 \times 24 \mathrm{~cm}$, compuesto de 250 páginas, 158 figuras y fotografias.

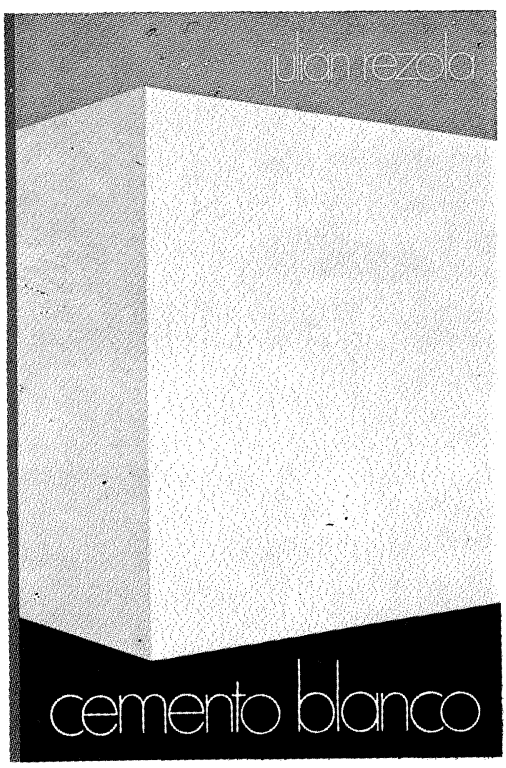

Cemento blanco

Julián Rezola

Ingeniero Químico Dipl. I. Q. S.

Sabido es que existe una extensa y documentada bibliografia sobre el cemento gris: en cambio, no puede decirse lo mismo acerca del cemento portland blanco, ya que los escritos existentes se refieren tan solo a algunas peculiaridades que le distinguen

El autor nos ofrece sus profundos conocimientos y su larga experiencia tanto en laboratorio como en fabricación.

La parte descriptiva del libro se complementa con gráficos, diagramas y fotografias de gran utilidad, destinados a conseguir la aplicación apropiada de este aglomerante.

Un volumen encuadernado en cartoné policerado, de numerosas figuras, tablas $y$ ábacos.

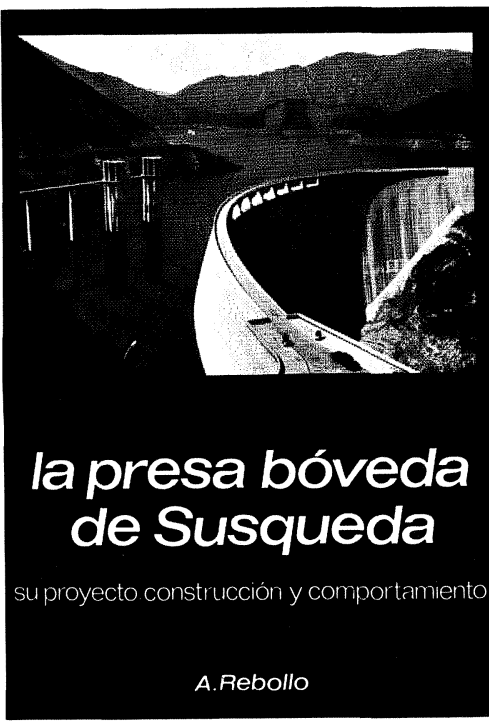

La presa bóveda de Susqueda

A. Rebollo,

Dr. Ingeniero de Caminos

El esfuerzo del constructor de presas se sitúa, por su pretensión de perennidad, a contracorriente de las tendencias de la civilización actual, caracterizada por lo fungible. Pueden evocarse las 10.000 grandes. presas en funcionamiento $o$ en construcción que están envejeciendo y reclaman los cuidados gerontológicos para mantener y perfeccionar su servicio y garantizar su inalienable pretensión de perennidad. En la medida en que todas nuevas obras, grandes o pequeñas, son portadoras de riesgos ecológicos $y$, a veces, catastróficos, que aumentan con el envejecimiento, la gerontologia de las presas es todo un emplazo. La acción adelantada de Arturo Rebollo en este terreno marca un camino a seguir para todos los que aman su propia obra con la devoción paternal que él ha puesto en Susqueda.

Un volumen encuadernado en cartoné plastificado con lomo de tela de 18 y $24,5 \mathrm{~cm}$ 408 páginas, 330 figuras y fotografias y 39 tablas. 